\title{
Star $\operatorname{Poly}(\boldsymbol{N}$-isopropylacrylamide) Tethered to Polyhedral Oligomeric Silsesquioxane (POSS) Nanoparticles by a Combination of ATRP and Click Chemistry
}

\author{
Shiao-Wei Kuo,, Jing-Long Hong, ${ }^{1}$ Yu-Chan Huang, ${ }^{1}$ Jem-Kun Chen,, ${ }^{2}$ Shih-Kang Fan, \\ Fu-Hsiang Ko, ${ }^{2}$ Chih-Wei Chu, ${ }^{2}$ and Feng-Chih Chang ${ }^{2}$ \\ ${ }^{1}$ Department of Materials and Optoelectronic Science, Center for Nanoscience and Nanotechnology, National Sun Yat-Sen University, \\ Kaohsiung 804, Taiwan \\ ${ }^{2}$ Institute of Applied Chemistry, National Chiao Tung University, Hsinchu 30010, Taiwan
}

Correspondence should be addressed to Shiao-Wei Kuo, kuosw@faculty.nsysu.edu.tw

Received 7 January 2012; Accepted 21 February 2012

Academic Editor: Luis Antonio Sanchez de Almeida Prado

Copyright (C) 2012 Shiao-Wei Kuo et al. This is an open access article distributed under the Creative Commons Attribution License, which permits unrestricted use, distribution, and reproduction in any medium, provided the original work is properly cited.

\begin{abstract}
New star poly( $N$-isopropylacrylamide)- $b$-polyhedral oligomeric silsesquioxane (PNIPAm- $b$-POSS) copolymers were synthesized from octa-azido functionalized POSS $\left(\mathrm{N}_{3}\right.$-POSS) and alkyne-PNIPAm, which was prepared using an alkyne-functionalized atom transfer radical polymerization (ATRP) initiator (propargyl 2-bromo-2-methylpropionamide), via click chemistry. These star PNIPAm- $b$-POSS copolymers undergo a sharp coil-globule transition in water at above $32^{\circ} \mathrm{C}$ changing from a hydrophilic state below this temperature to a hydrophobic state above it, which is similar to linear PNIPAm homopolymers. More interestingly, we found that these star polymers exhibited strong blue photoluminescence in water above a lower critical solution temperature (LCST). This photoluminescence was likely due to the constrained geometric freedom and relatively rigid structure caused by intramolecular hydrogen bonding within the star PNIPAm polymers, which exhibit an intrinsic fluorescent behavior.
\end{abstract}

\section{Introduction}

The PNIPAm homopolymer undergoes a sharp coil-globule transition in water at $32^{\circ} \mathrm{C}$, transitioning from a hydrophilic state below this temperature to a hydrophobic state above it [1-5]. The lower critical solution temperature (LCST) corresponds to the region in the phase diagram where the enthalpic contribution of the hydrogen bonds between water and the polymer chain is less than the entropic gain of the system as a whole and is largely dependent on the hydrogenbonding capabilities of the constituent monomer units. Unlike hyperbranched polymers, star polymers also possess unique structures within the regular polymer branches as each polymer chain has only one branching point. Welldefined star polymers can be used as models to test theories about the influence of molecular structure on polymer properties [6-10].

POSS-containing copolymers have received increasing attention during the past decade as a novel category of nanoscale-structured materials for various applications [11], including liquid crystals [12], low-dielectric materials [1316], nanocomposites [17], self-assembled structures [18-20], and photoresists in lithographic technology [21,22], because of their thermal and mechanical properties. POSS is an inorganic $\mathrm{Si}_{8} \mathrm{O}_{12}$ core that can be functionalized by attaching either seven inert organic hydrocarbon groups and a unique functional group or eight functional groups that are capable of polymerization or crosslinking [23-30]. It is in this latter regard that we have sought to develop star polymers consisting of well-defined PNIPAm functionalized cubic silsesquioxanes. PNIPAm/POSS nanocomposites have been widely reported in recent years [31-34]. For example, Zheng and colleagues have reported that PNIPAm/POSS nanocomposites were prepared through the reaction between the N$\mathrm{H}$ group of PNIPAm and the epoxy group of octa(propylglycidyl ether)-POSS, swelled in water, and exhibited the characteristics of hydrogels [31]. These POSS-containing, hybrid hydrogels showed substantially faster swelling, 


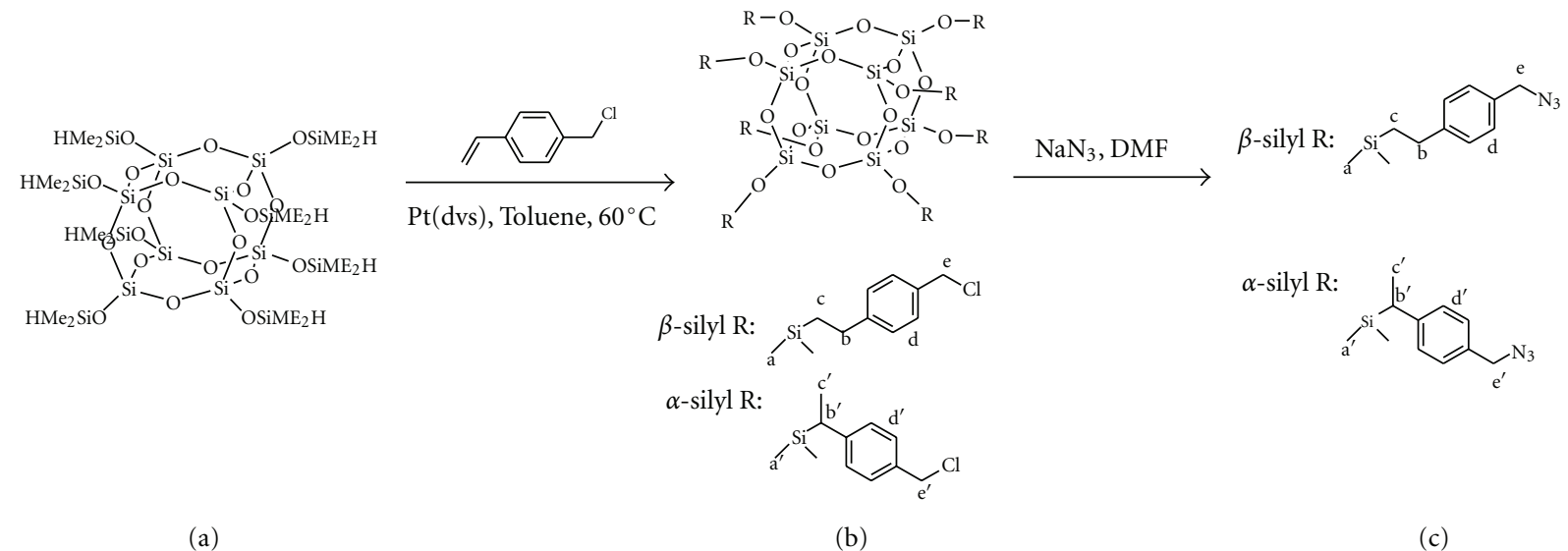

Scheme 1: Hydrosilylation of styrene monomers with (a) $\mathrm{Q}_{8} \mathrm{M}_{8}{ }^{\mathrm{H}}$ to give the (b) OVBC-POSS and the (c) $\mathrm{N}_{3}$-POSS.

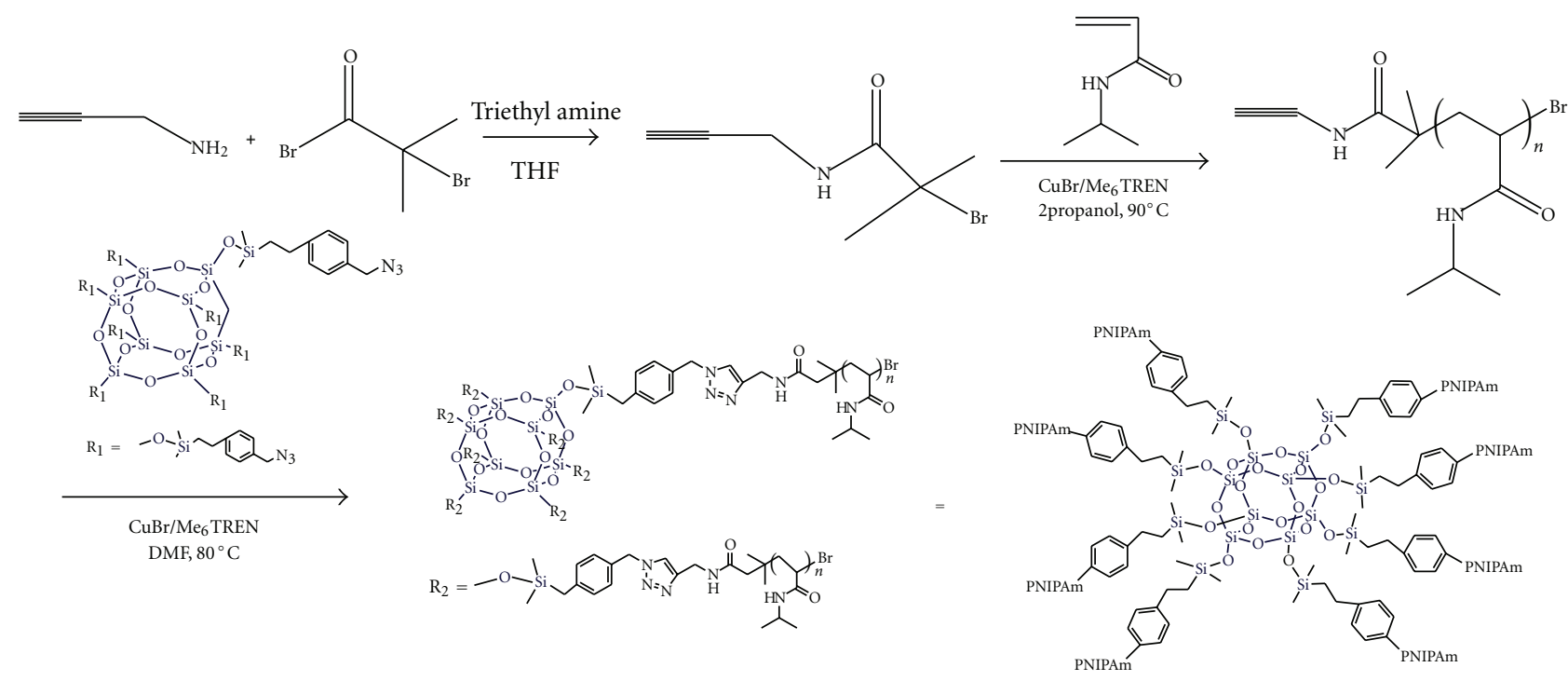

Scheme 2: The synthesis of the alkyne PNIPAm through ATRP and the click reaction to form star PNIPAm- $b$-POSS.

deswelling, and reswelling response rates than a control organic gel with a comparable degree of crosslinking. POSS; end-capped poly(ethylene oxide) was also incorporated into the crosslinked PNIPAm to form a physically interpenetrating polymer network [32]. Zhang et al. used a POSScontaining reversible addition fragmentation chain transfer (RAFT) agent in the RAFT polymerization of NIPAm to form a POSS-end-capped PNIPAm hybrid, which assembled into well-defined core/shell nanostructured micelles in solvents, with the average diameter of the micelles increasing with increasing molecular weight of the PNIPAm [34].

In this work, we prepared POSS nanoparticles functionalized with eight PNIPAm polymer chains through a combination of atom transfer radical polymerization (ATRP) and click chemistry. To the best of our knowledge, this is the first paper that reports the star PNIPAm-POSS polymers through combination of ATRP and click chemistry. First, we synthesize a multifunctional octa-azide POSS ( $\mathrm{N}_{3}$-POSS) molecule, shown in Scheme 1, $[35,36]$, and then clicked it to an
alkyne-PNIPAm polymer, which had been prepared using an alkyne-terminal ATRP initiator as shown in Scheme 2. The molecular weight, chemical structure and photoluminescence properties of star PNIPAm- $b$-POSS were characterized in this study by gel permeation chromatography (GPC), Fourier transform infrared spectroscopy (FTIR), nuclear magnetic resonance (NMR) spectroscopy, and fluorescence spectroscopy (PL).

\section{Experimental}

2.1. Materials. Vinyl benzyl chloride (VBC), N,N-dimethylformamide, sodium azide $\left(\mathrm{NaN}_{3}\right)$, copper (I) bromide $(\mathrm{CuBr}, 98 \%), N, N, N^{\prime}, N^{\prime \prime}, N^{\prime \prime}$-pentamethyldiethylenetriamine (PMDETA, 99\%), and platinum complex (platinum1,3-divinyltetramethyldisiloxane, Pt-dvs, $2 \mathrm{wt} \% \mathrm{Pt}$ in xylene) were purchased from Aldrich, USA. Before use, the solution of the platinum complex was diluted 100-fold with xylene. Toluene was dried by distillation before using in 


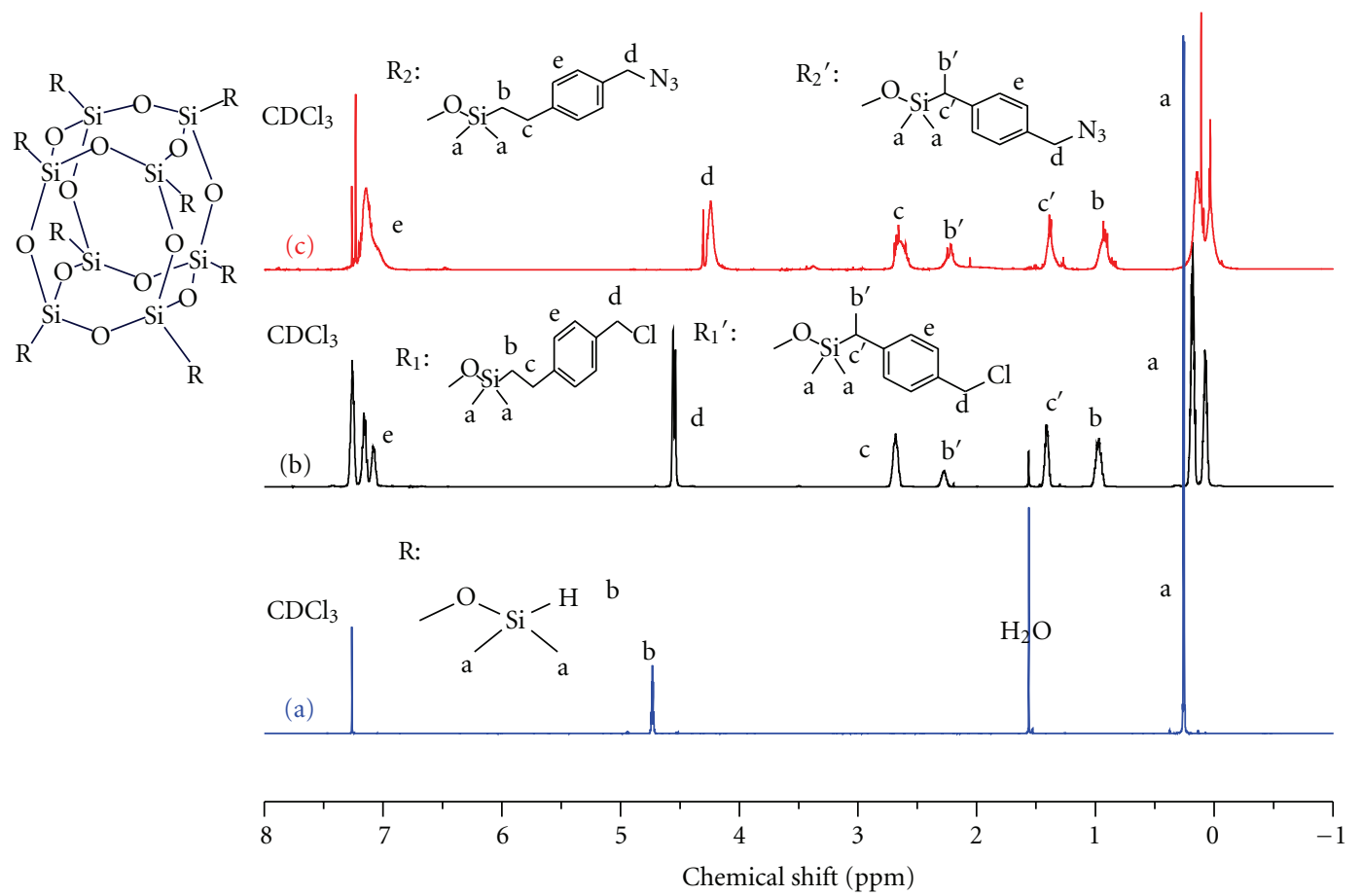

Figure 1: ${ }^{1} \mathrm{H}$ NMR spectra of (a) $\mathrm{Q}_{8} \mathrm{M}_{8}{ }^{\mathrm{H}}$, (b) OVBC-POSS, and (c) $\mathrm{N}_{3}$-POSS in $\mathrm{CDCl}_{3}$.

the hydrosilylation reaction. Octakis(dimethylsiloxy)silsesquioxane $\left(\mathrm{Q}_{8} \mathrm{M}_{8}{ }^{\mathrm{H}}\right)$ containing eight hydrosilane groups was purchased from the Hybrid Plastics Co., USA. N-isopropylacrylamide (NIPAm) monomer was obtained from the Tokyo Chemical Industrial CO., Ltd. The NIPAm monomer was recrystallized from hexanes and dried in vacuum prior to use. Hexamethylated tris(2-(dimethylamino)ethyl)amine ( $\mathrm{Me}_{6}$ TREN) was synthesized according to the method by Ciampolini and Nardi [37]. Propargyl 2-bromo-2-methylpropionamide was prepared according to the literature procedure $[2,3]$.

2.2. Synthesis of $N_{3}$-POSS $[35,36] . \mathrm{N}_{3}$-POSS was synthesized by reacting OVBC-POSS with sodium azide $\left(\mathrm{NaN}_{3}\right)$ as shown in Scheme 1. The OVBC-POSS was prepared by mixing $\mathrm{Q}_{8} \mathrm{M}_{8}{ }^{\mathrm{H}}(1 \mathrm{~g}, 0.98 \mathrm{mmol})$ with vinyl-benzyl-chloride $(1.20 \mathrm{~g}, 7.86 \mathrm{mmol})$ in toluene $(50 \mathrm{~mL})$ while heating at $60^{\circ} \mathrm{C}$ under argon and then adding $\mathrm{Pt}(\mathrm{dvs})(0.07 \mathrm{~mL}, 0.13 \mathrm{mmol})$ via syringe. After stirring for $4 \mathrm{~h}$, the $\mathrm{Pt}(\mathrm{dvs})$ catalyst was removed by filtering through activated charcoal; subsequent removal of the solvent via rotary evaporation yielded a viscous liquid. The chemical structure of the OVBC-POSS was determined using ${ }^{29} \mathrm{Si} \mathrm{NMR}$ spectroscopy and possessed two peaks, one each for $\left(\mathrm{CH}_{3}\right)_{2} \mathrm{Si}-\mathrm{H}$ and $\mathrm{Si}-\mathrm{O}-\mathrm{Si}\left(\mathrm{CH}_{3}\right)_{2} \mathrm{H}$ at -2.1 and $109.3 \mathrm{ppm}$, respectively. In addition, the ${ }^{29} \mathrm{Si}$ NMR spectrum had three peaks at $10.28,12.16$, and $-109.2 \mathrm{ppm}$ corresponding to $\left(\mathrm{CH}_{3}\right)_{2} \mathrm{Si}-\left(\mathrm{CHCH}_{3}\right),\left(\mathrm{CH}_{3}\right)_{2} \mathrm{Si}-\mathrm{CH}_{2}-$ $\mathrm{CH}_{2}-$, and $\mathrm{Si}-\mathrm{O}-\mathrm{Si}\left(\mathrm{CH}_{3}\right)_{2} \mathrm{H}$, respectively. The chemical shifts clearly indicate that the hydrosilylation reaction went to completion under the reaction conditions. In a typical synthesis of $\mathrm{N}_{3}$-POSS, OVBC-POSS ( $1 \mathrm{~g}, 0.45 \mathrm{mmol}$ ), $\mathrm{NaN}_{3}$ $(1.01 \mathrm{~g}, 15.4 \mathrm{mmol})$, and anhydrous DMF $(50 \mathrm{~mL})$ were added to a flask and heated at $120^{\circ} \mathrm{C}$ for $48 \mathrm{~h}$. The solvents were then concentrated, and the residue was dissolved in THF. The sodium salts were removed by running through a neutral alumina column. A yellowish viscous liquid was obtained after drying in a vacuum oven overnight at room temperature.

2.3. Synthesis of Alkyne-PNIPAm [38]. A $100 \mathrm{~mL}$ dried Schlenk flask containing a magnetic stirrer bar was charged with $\mathrm{CuBr}$ (14.3 mg, $0.1 \mathrm{mmol})$ and NIPAM (1.35 g, $12 \mathrm{mmol})$. After filling the flask with argon, IPA $(3 \mathrm{~mL})$ was added, and the solution was stirred for $10 \mathrm{~min}$ at room temperature. The mixture was degassed three times using a freeze-pump-thaw cycle and then vigorously stirred at $0^{\circ} \mathrm{C}$. After complete degassing, $\mathrm{Me}_{6}$ TREN (23.0 mg; $0.1 \mathrm{mmol}$ ) was injected into the solution with a syringe. After 10 minutes, the desired amount of propargyl 2-bromo-2-methylpropionamide was injected into the solution to initiate the reaction. The mixture was heated at $50^{\circ} \mathrm{C}$ for $12 \mathrm{~h}$ and then evaporated to dryness under vacuum. The residue was diluted with THF and then passed through an alumina column to remove the copper catalyst. The product was precipitated from ether three times and dried under vacuum overnight at room temperature to obtain the polymer as a white powder.

2.4. Synthesis of Star PNIPAm-b-POSS Copolymers. $\mathrm{N}_{3}$ POSS (0.0115 g), alkyne-PNIPAm (0.5 g), and CuBr (3.5 mg, $0.025 \mathrm{mmol})$ were dissolved in DMF $(20 \mathrm{~mL})$ in a flask equipped with a magnetic stir bar. After one freeze-thawpump cycle, PMDETA $(5.2 \mu \mathrm{L}, 0.025 \mathrm{mmol})$ was added, and the reaction mixture was carefully degassed using three freeze-thaw-pump cycles, placed in an oil bath thermostated 


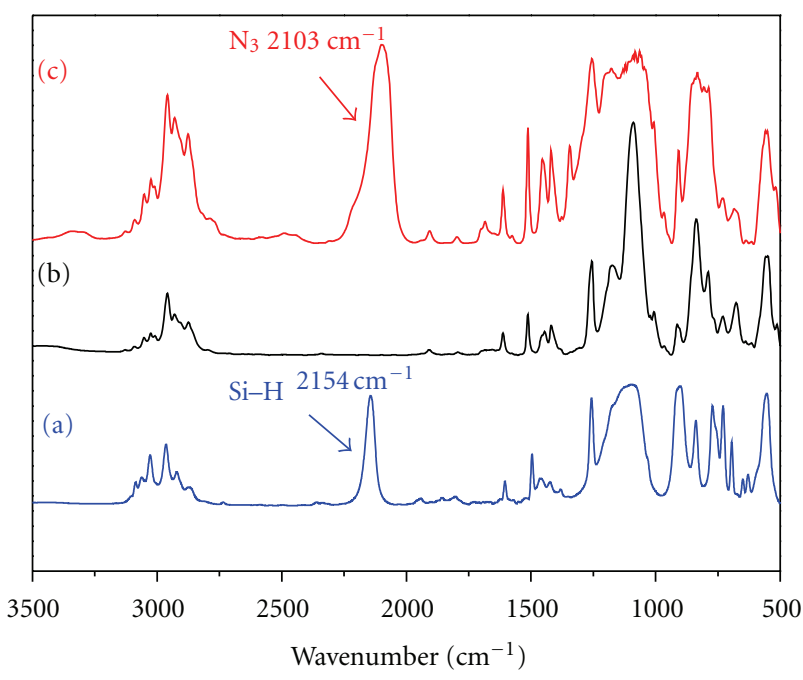

FIGURE 2: FTIR spectra of (a) $\mathrm{Q}_{8} \mathrm{M}_{8}{ }^{\mathrm{H}}$, (b) OVBC-POSS, and (c) $\mathrm{N}_{3}$ POSS recorded at room temperature.

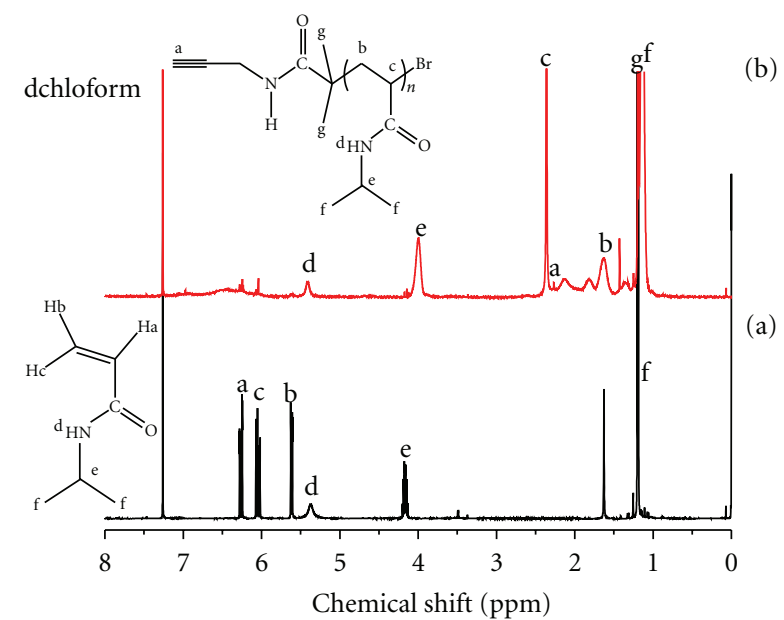

FIGURE 3: ${ }^{1} \mathrm{H}$ NMR spectra of (a) NIPAm monomer and (b) alkynePNIPAm in $\mathrm{CDCl}_{3}$.

at $60^{\circ} \mathrm{C}$ and stirred for $24 \mathrm{~h}$. After removing all of the solvents at reduced pressure, the residue was dissolved in $\mathrm{CH}_{2} \mathrm{Cl}_{2}$ and passed through a neutral alumina column to remove the copper catalyst. The star PNIPAm- $b$-POSS was obtained as a dark powder.

2.5. Characterizations. Using $\mathrm{CDCl}_{3}$ as the solvent, ${ }^{1} \mathrm{H} \mathrm{NMR}$ spectra were recorded on a Varian Unity Inova 500 FT NMR spectrometer operated at $500 \mathrm{MHz}$; chemical shifts are reported in parts per million (ppm). The molecular weight and molecular weight distribution were determined through gel permeation chromatography (GPC) using a Waters 510 HPLC equipped with a 410 differential refractometer, a refractive index (RI) detector, and three Ultrastyragel columns $\left(100,500\right.$, and $\left.10^{3} \AA\right)$ connected in series in order of increasing pore size (eluent: DMF, flow rate: $0.6 \mathrm{~mL} / \mathrm{min}$ ). The FT-IR spectra of the samples in $\mathrm{KBr}$ disks were measured using a Nicolet Avatar 320 FT-IR spectrometer and collecting 32 scans at a resolution of $1 \mathrm{~cm}^{-1}$ after the sample chamber

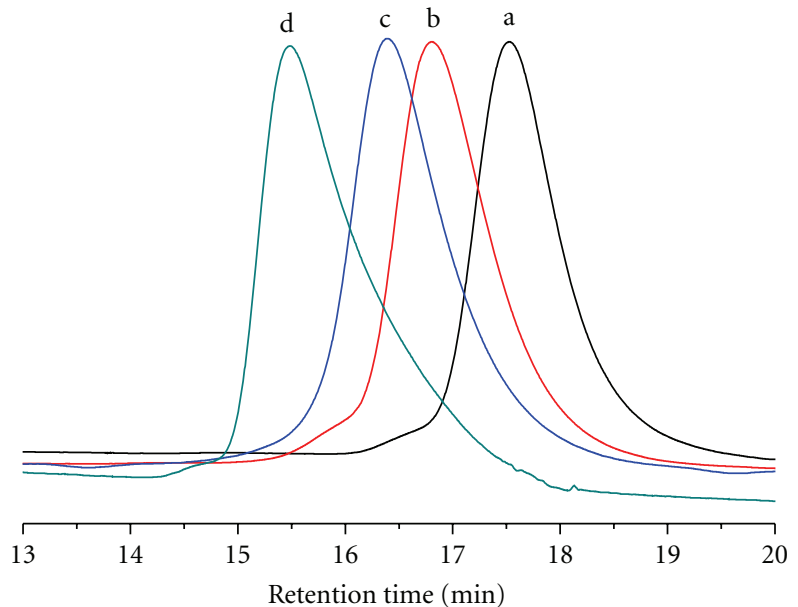

FIGURE 4: GPC traces of the molecular weight for the alkyne-PNIPA (a) 3100, (b) 5100, (c) 6300, and (d) $10100 \mathrm{~g} / \mathrm{mol}$.

had been purged with nitrogen to maintain the film's dryness. Thermal analysis was carried out using a DSC instrument (TA Instruments Q-20). The sample (ca. 4-6 mg) was weighed and sealed in an aluminum pan, and the measurement was obtained using a scan rate of $20^{\circ} \mathrm{C} / \mathrm{min}$ and a temperature range of 25 to $200^{\circ} \mathrm{C}$. The glass transition temperature $\left(T_{g}\right)$ was taken as the midpoint of the heat capacity transition between the upper and lower points of deviation in the extrapolated glass and liquid lines. Dynamic Light Scattering (DLS) measurements were performed using a Brookhaven 90 plus Particle Size Analyzer (Brookhaven Instruments Corporation, USA) equipped with a $35 \mathrm{~mW}$, $632.8 \mathrm{~nm}$ He-Ne laser. The temperature was controlled by the heating and cooling process, and the measurements were obtained at a $90^{\circ}$ angle. Photoluminescence (PL) excitation and emission spectra were collected at room temperature using a monochromatized Xe light source.

\section{Results and Discussion}

3.1. Synthesis of $\mathrm{N}_{3}$-POSS. The peaks for the $\mathrm{Si}-\mathrm{H}$ protons $(4.7 \mathrm{ppm})$ in Figure 1(a) disappeared in the spectrum of OVBC-POSS, which indicates that the hydrosilylation reaction went to completion. The spectrum in Figure 1(b) indicates that the vinyl groups of the VBC underwent hydrosilylation with the Si-H bonds of the $\mathrm{Q}_{8} \mathrm{M}_{8}{ }^{\mathrm{H}}$ in both the $\alpha$ and $\beta$ configurations; that is, a mixture of these two orientations exists. The complete substitution of the chloride atoms by the azido groups was confirmed by the ${ }^{1} \mathrm{H}$ NMR spectrum, shown in Figure 1(c). After the substitution reaction, the resonance of the benzyl $\mathrm{CH}_{2}$ connected to the chloride atoms shifted upfield, from 4.50 to $4.31 \mathrm{ppm}[35,36]$. The complete loss of the resonance at $4.50 \mathrm{ppm}$ suggests that the substitution reaction went to completion under the reaction conditions. Figure 2 presents the FTIR spectra of $\mathrm{Q}_{8} \mathrm{M}_{8}{ }^{\mathrm{H}}$, OVBC-POSS, and $\mathrm{N}_{3}$-POSS. The strong absorption peak in all compounds around $1100 \mathrm{~cm}^{-1}$ represents the siloxane $\mathrm{Si}-\mathrm{O}-\mathrm{Si}$ vibration and is a general feature of POSS derivatives. The characteristic stretching vibrations for the $\mathrm{Si}-\mathrm{H}$ group appeared as the peak at $2200 \mathrm{~cm}^{-1}$, as shown 


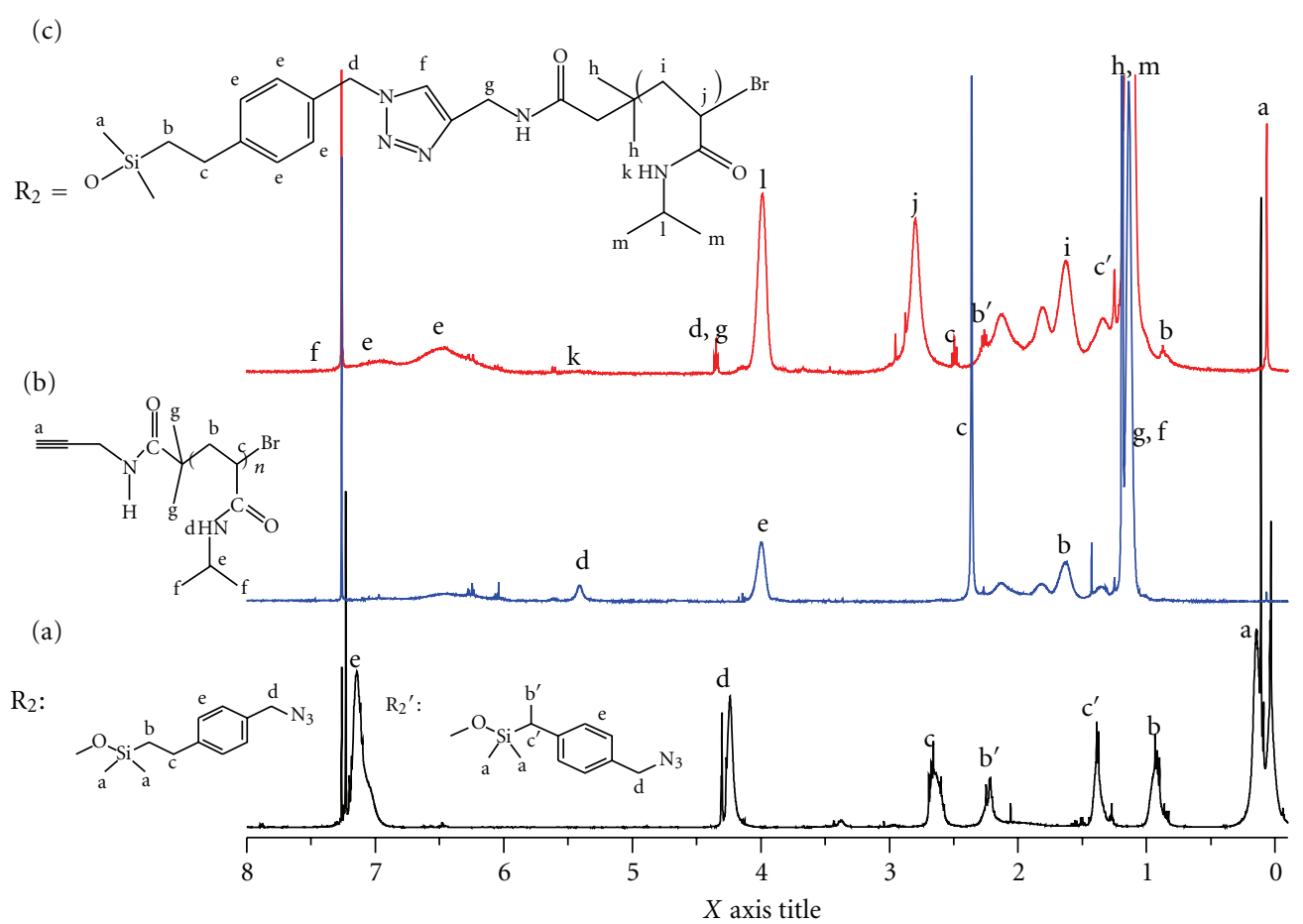

FIGURE 5: ${ }^{1} \mathrm{H}$ NMR spectra of (a) $\mathrm{N}_{3}$-POSS, (b) alkyne-PNIPAm, and (c) star PNIPAm- $b$-POSS in $\mathrm{CDCl}_{3}$.

in Figure 2(a). In the spectrum for OVBC-POSS, this peak disappeared completely, which indicates that the reaction reached completion. The $\mathrm{N}_{3}$-POSS clearly showed a peak at $2096 \mathrm{~cm}^{-1}$, indicative of the presence of azido groups, after the substitution reaction, as shown in Figure 2(c). All results based on the ${ }^{1} \mathrm{H}$ NMR and FTIR analyses were indicative of the successful synthesis of $\mathrm{N}_{3}$-POSS.

3.2. Synthesis of Alkyne-PNIPAm. The alkyne-terminated PNIPAm was prepared using an alkyne functionalized ATRP initiator (propargyl 2-bromo-2-methylpropionamide). Figure 3(a) shows the peaks for the vinyl NIPAm monomer (ca. 5.61, 6.04, and $6.25 \mathrm{ppm}$ ), which disappear completely after chain extension via ATRP. The other alkyl $\mathrm{CH}$ and $\mathrm{CH}_{2}$ protons in the NIPAm monomer appeared as multiplets at 4.17 and $1.17 \mathrm{ppm}$, respectively, while the singlet at $5.37 \mathrm{ppm}$ belonged to the proton on the amide nitrogen atom. These three peaks remained in the spectrum for the alkyne-PNIPAm, as shown in Figure 3(b). The singlet at $2.25 \mathrm{ppm}$ corresponds to the $\mathrm{C} \equiv \mathrm{C}-\mathrm{H}$ while the alkyl $\mathrm{CH}$ and $\mathrm{CH}_{2}$ on the alkyne-PNIPAm main chain were located between 1.60 and $2.34 \mathrm{ppm}$, respectively. The GPC curves of alkyne-PNIPAm synthesized from different monomer/initiator ratios are both symmetrical and monomodal, as shown in Figure 4. The molecular weight increases with increasing monomer/initiator ratios, which is consistent with the principles of ATRP. Furthermore, the PDI of the alkyne-PNIPAm is narrow, which indicates successful chain extension of the PNIPAm through ATRP. These results are summarized in Table 1.

3.3. The Synthesis and Thermoresponsive Properties of Star PNIPAm-b-POSS Copolymers. The azide/alkyne click reaction was performed at $0^{\circ} \mathrm{C}$ over $24 \mathrm{~h}$ using $\mathrm{CuBr} / \mathrm{PMDETA}$
TABLE 1: Molecular characterization of the alkyne-PNIPAm homopolymer during ATRP.

\begin{tabular}{lccccc}
\hline & Monomer: initiator & $M_{w}{ }^{\mathrm{a}}$ & $M_{n}{ }^{\mathrm{a}}$ & $\mathrm{PDI}^{\mathrm{a}}$ & $T_{g}{ }^{\mathrm{b}}$ \\
\hline PNIPAM1 & $200: 1$ & 11700 & 10100 & 1.15 & 140 \\
PNIPAM2 & $100: 1$ & 7300 & 6300 & 1.16 & 141 \\
PNIPAM3 & $80: 1$ & 5700 & 5100 & 1.12 & 140 \\
PNIPAM4 & $50: 1$ & 3600 & 3100 & 1.14 & 112 \\
\hline
\end{tabular}

${ }^{\mathrm{a}}$ Polydispersity index and molecular weight, measured by GPC. ${ }^{\mathrm{b}}$ Obtained from DSC by $20^{\circ} \mathrm{C} / \mathrm{min}$.

as a catalyst and DMF as the solvent and was confirmed with ${ }^{1} \mathrm{H},{ }^{13} \mathrm{C}$ NMR and FTIR [39]. The peak assignments of $\mathrm{N}_{3}-$ POSS and alkyne-PNIPAm have been shown in Figures 1 and 3. In addition, the peaks of star PNIPAm- $b$-POSS are assigned in Figure 5(c). Because the molecular weight of the PNIPAm was very low, the proton signals of the POSS are clearly displayed in Figure 5(c). With the exception of the overlapping proton signals around 1.63 and $2.80 \mathrm{ppm}$, the PNIPAm peaks are easily identified. The resonance of the benzyl $\mathrm{CH}_{2}$ connected to the azide in the $\mathrm{N}_{3}$-POSS shifted downfield, from 4.23 to $4.38 \mathrm{ppm}$, in the star PNIPAm- $b$ POSS spectrum. In addition, the methyl $\left(\mathrm{CH}_{3}\right)$ attached to the silicone atom was found at $0.04 \mathrm{ppm}$ from $\mathrm{N}_{3}$-POSS, which also indicates the synthesis of star PNIPAm- $b$-POSS was successful. The click reaction was also characterized by ${ }^{13} \mathrm{C}$ NMR, as shown in Figure 6. The carbonyl and amide carbon signals in the star PNIPAm- $b$-POSS spectrum appeared at 174 and $170 \mathrm{ppm}$, respectively, while the phenyl rings showed up at 126 and $128 \mathrm{ppm}$. Clearly, the alkyne carbon signal at $81.0 \mathrm{ppm}$ in the alkyne-PNIPAm spectrum disappeared in the star PNIPAm- $b$-POSS spectrum. The peak at $143.5 \mathrm{ppm}$ is from the carbon of the triazole structures 


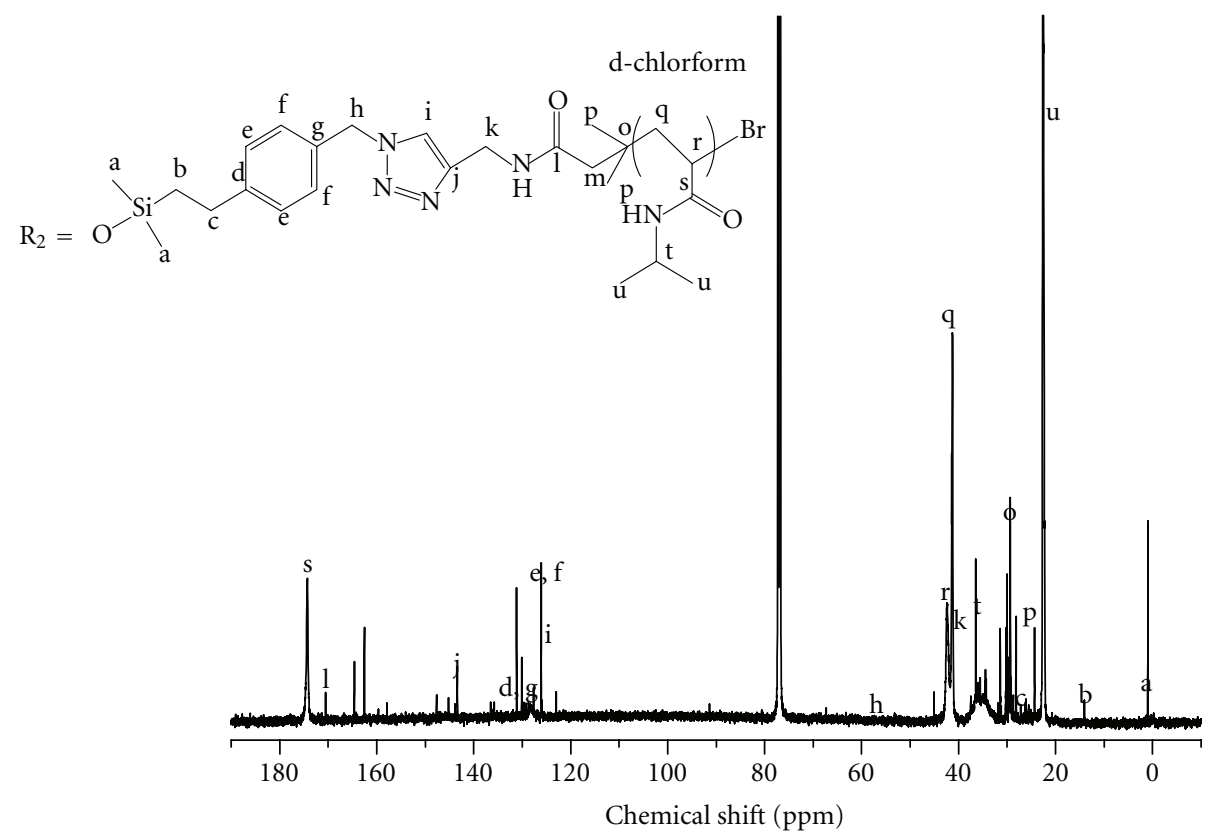

Figure 6: ${ }^{13} \mathrm{C}$ NMR spectrum of star PNIPAm- $b$-POSS in $\mathrm{CDCl}_{3}$.

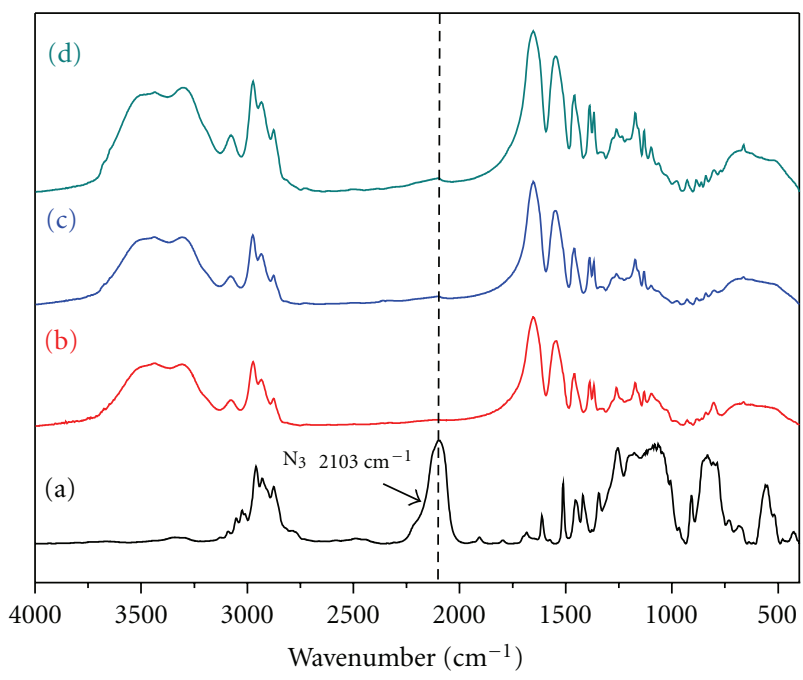

FIgURE 7: FTIR spectra of (a) $\mathrm{N}_{3}$-POSS, (b) PNIPAm (3.1 k)- $b$ POSS, (c) PNIPAm (6.3 k)-b-POSS, and (d) PNIPAm (10.1 k)-bPOSS.

formed by the click reaction. The peaks for the $\mathrm{N}_{3}$-POSS methyl and methylene carbons remained at $0.2 \mathrm{ppm}$ and 14.0 ppm, respectively, in the star PNIPAm- $b$-POSS spectrum. All other carbon signals for the star PNIPAm- $b$-POSS are assigned in Figure 6. The complete disappearance of the characteristic FTIR signals for the azide and acetylene groups is shown in Figure 7. The peak at $2100 \mathrm{~cm}^{-1}$, which corresponds to the azide in $\mathrm{N}_{3}$-POSS, completely disappeared from the spectrum for the star PNIPAm- $b$-POSS copolymers while the characteristic Si-O-Si (siloxane) absorption for POSS, which appears at $1100 \mathrm{~cm}^{-1}$, remained. These results indicate that all the azide and acetylene functionalities participated in the click reaction $[30,39]$. In addition, the

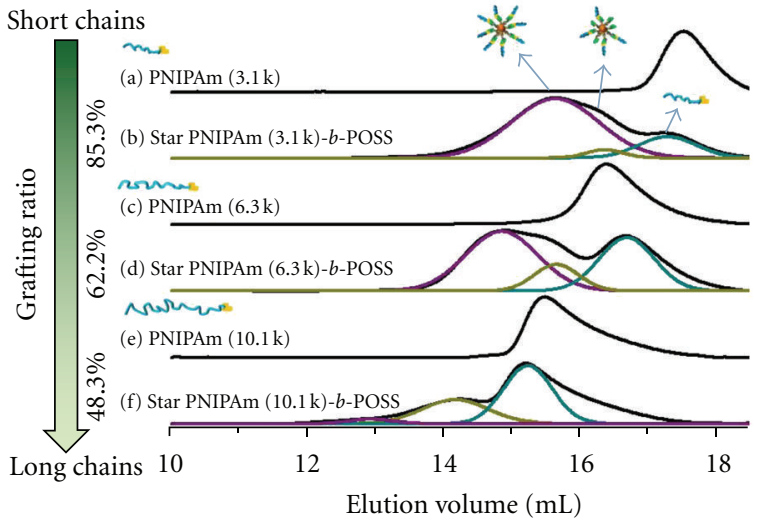

FIGURE 8: GPC traces of (a) alkyne-PNIPAm and (b) star PNIPAm $(3.1 \mathrm{k})-b$-POSS.

FTIR spectra in Figure 7 show the appearance of two new peaks at 1653 and $1550 \mathrm{~cm}^{-1}$, which corresponds to the stretching vibration of the amide I and amide II groups of the PNIPAm in the star PNIPAm- $b$-POSS copolymers. The GPC trace of the star PNIPAm- $b$-POSS block copolymer obtained after the click reaction is shown in Figure 8. Block copolymers prepared from the alkyne-PNIPAm resulted in products nearly devoid of the alkyne-PNIPAm peak and with lower retention times, which supports the formation of star PNIPAm- $b$-POSS copolymers. Because of the clear separation between ungrafted PNIPMm peas and the star PNIPAmb-POSS copolymer, we are able to quantify the contents of grafted PNIPAm ratios. On the GPC traces, the peaks at shorter and longer retention times in each GPC trace corresponded to the elution of the full PNIPAm-b-POSS and partial PNIPAm-b-POSS as shown in Figure 8(b) and 


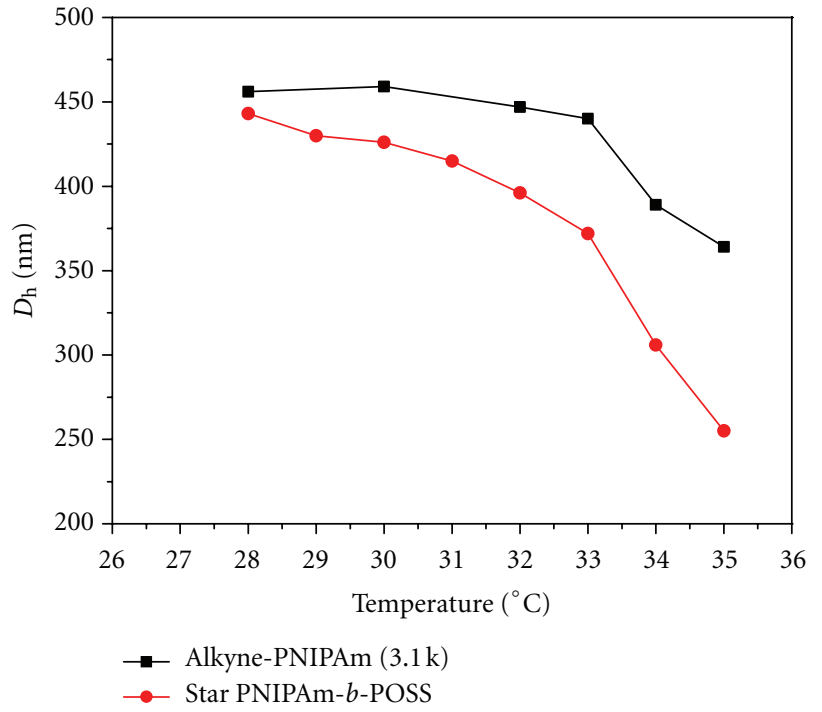

FIgURE 9: Variation of the average hydrodynamic diameter $\left(D_{h}\right)$ with the temperature of the alkyne-PNIPAm and the star PNIPAm$b$-POSS.

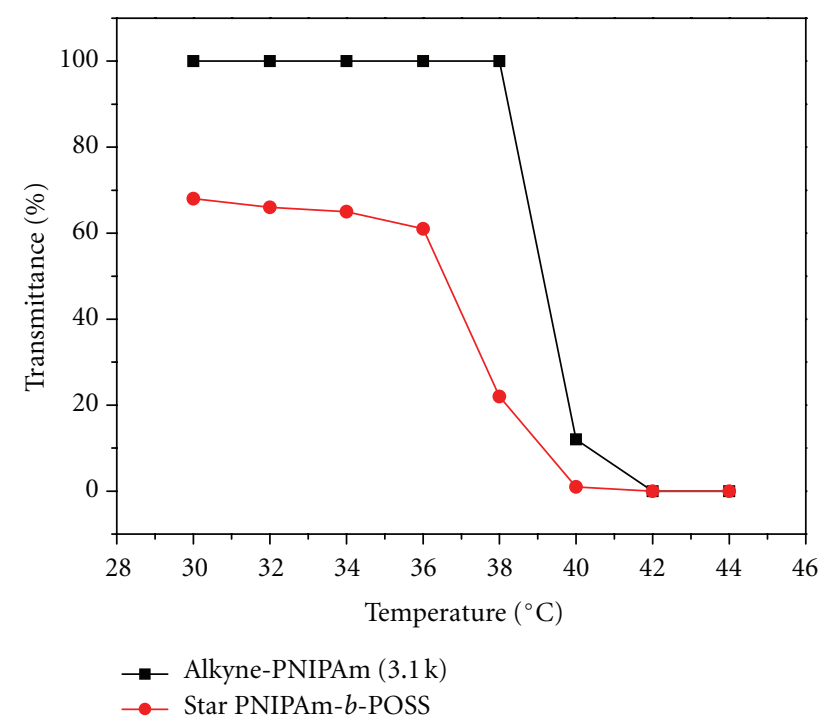

FIgURE 10: Transmittance versus temperature of the alkynePNIPAm and the star PNIPAm- $b$-POSS.

smaller ungrafted alkyne-PNIPAm, respectively. The ratio of grafted PNIPAm was determined by comparing the grafted PNIPAm peak ratio after using Gaussian fitting. Comparing the different chain length of the alkyne-PNIPAm to POSS provides an indication that the polymer's molecular weight has an influence on the grafted ratio of the star PNIPAm$b$-POSS copolymers. Clearly, as the molecular weight of PNIPAm is increased, the graft ratio is decreased (85.3 to $48.3 \%$ ). This result can be explained by the decreased reactivity of the chain-end alkyne functionality that becomes less accessible as the polymer adopts a more random coil structure at high molecular weight [40]. All of the results from the ${ }^{1} \mathrm{H}$ NMR, ${ }^{13} \mathrm{C}$ NMR, FTIR, and GPC analyses indicated that the synthesis of star PNIPAm- $b$-POSS was successful.

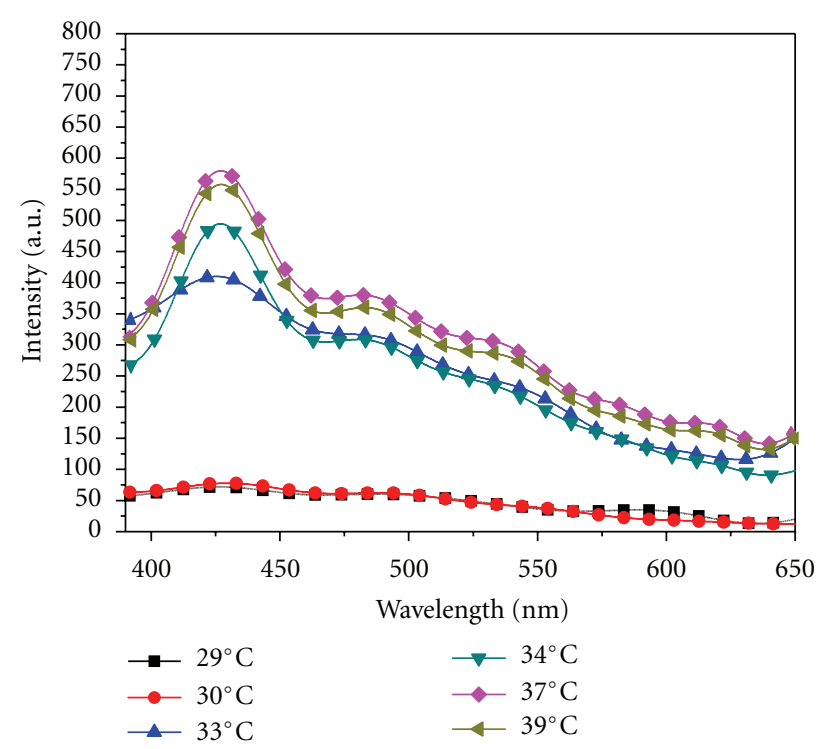

FIGURE 11: PL spectra of the alkyne-PNIPAm with increasing temperature.

Dynamic light scattering (DLS) was employed to determine both the hydrodynamic diameter $\left(\left\langle D_{h}\right\rangle\right)$ of the alkynePNIPAm and star PNIPAm- $b$-POSS and their temperatureresponsive behavior. As shown in Figure 9, increasing the temperature from 26 to $36^{\circ} \mathrm{C}$ decreased the average hydrodynamic diameter of pure alkyne-PNIPAm from 460 to $340 \mathrm{~nm}$ and star PNIPAm- $b$-POSS copolymers from $440 \mathrm{~nm}$ to $200 \mathrm{~nm}$, which corresponds to the "deswelling" states of PNIPAm $[1,5]$. Both the linear and star PNIPAm clearly displayed dimensional change with temperature, implying that the volumes of these PNIPAm polymers can shrink or swell with changing temperature. Most importantly, the size dependence of the PNIPAm during the heating process coincides reversibly with that during the cooling process. Therefore, after a cycle of temperature increases and decreases, the hydrodynamic diameter returns to its starting value [1]. In addition, the star PNIPAm- $b$-POSS copolymer has a lower hydrodynamic diameter than the linear alkyne-PNIPAm, indicating that the star polymers can collapse into a denser globule as a result of the star architecture [41]. Also, pure alkyne-PNIPAm homopolymers are highly water soluble at temperatures below $38^{\circ} \mathrm{C}$. The transparent aqueous alkynePNIPAm solution becomes opaque above a specific temperature, as shown in Figure 10, and becomes transparent again when the temperature decreases, which corresponds to a reversible phase transition. The star PNIPAm- $b$-POSS copolymer had lower transmittance than the linear alkynePNIPAm since the POSS and benzyl functional groups are not water soluble, which would decrease their transmittance; however, it also had a similar phase transition to the pure alkyne-PNIPAm at ca. $38^{\circ} \mathrm{C}$. Scheme 3 shows the possible phase transitions of star PNIPAm- $b$-POSS with increasing temperature. The random coils of the star PNIPAm chains first collapse to form a dense globule at ca. $32^{\circ} \mathrm{C}$ and then phase separated from the aqueous solution at $\mathrm{ca} .38^{\circ} \mathrm{C}$. We found that the LCST increased with decreasing molecular 


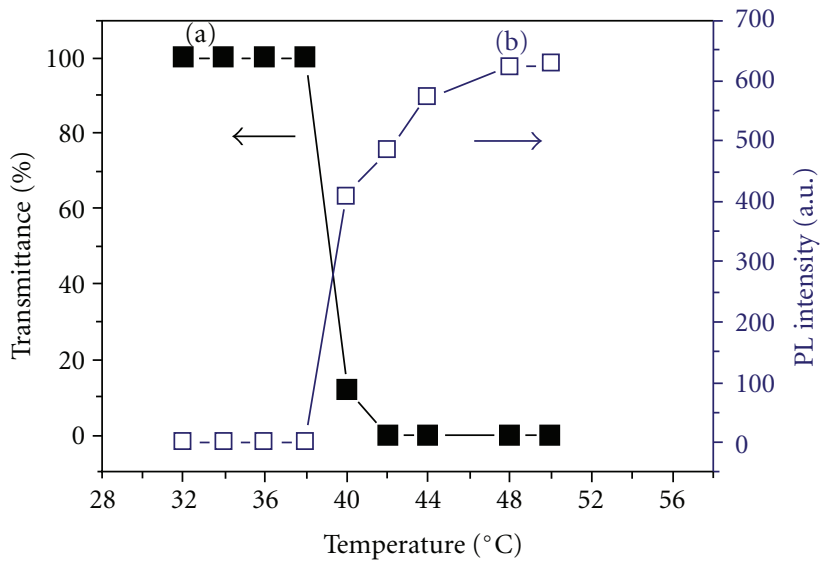

(a)

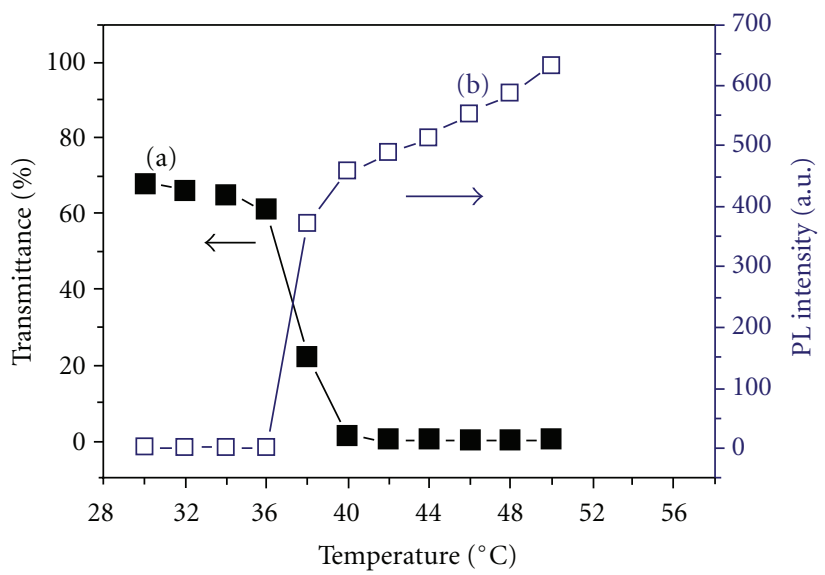

(c)

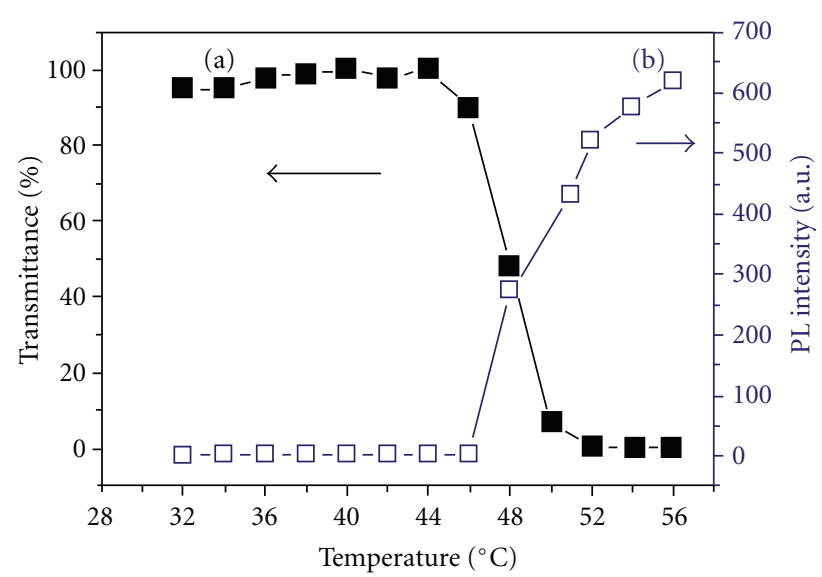

(b)

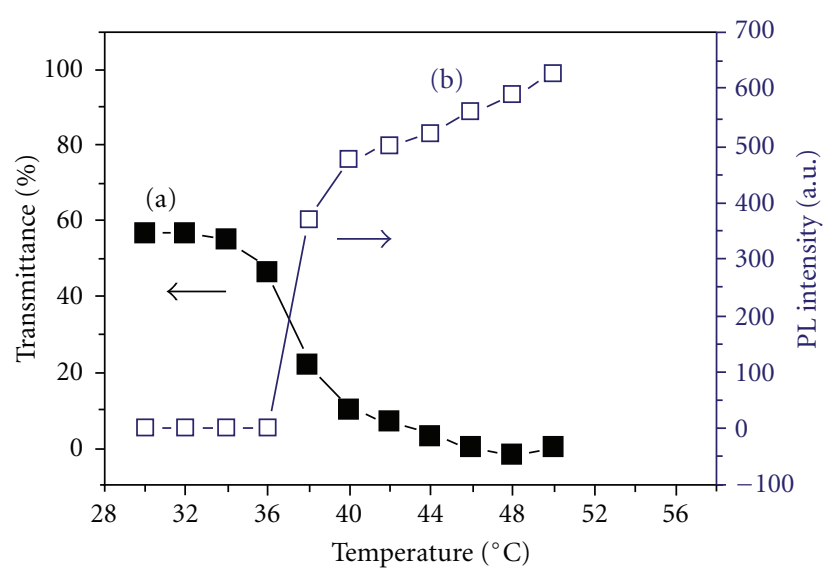

(d)

FIGURE 12: Transmittance and PL intensity with increasing temperature of the (a) alkyne-PNIPAm (10.1 k), (b) alkyne-PNIPAm (3.1 k), (c) star PNIPAm (10.1 k)-b-POSS, and (d) star PNIPAm (3.1 k)-b-POSS.

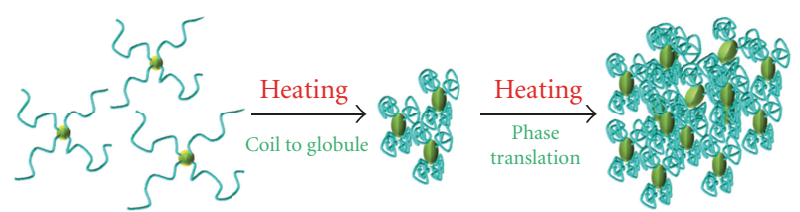

Scheme 3: The possible phase transitions of the star PNIPAm- $b$ POSS with increasing temperature.

weight for both the alkyne-PNIPAm and the star PNIPAm$b$-POSS because the low molecular weight is more difficult to phase-separate due to entropy constraints.

Figure 11 shows the PL spectra of the alkyne-PNIPAm with increasing temperature. Clearly, no emission was observed below $32^{\circ} \mathrm{C}$ while a high-intensity emission appeared above $32^{\circ} \mathrm{C}$, which means that the aggregation of the PNIPAm chain could enhance the emission properties of the material. Figure 12 summarizes the transmittance and PL intensity of the alkyne-PNIPAm and the star PNIPAm- $b$ POSS with increasing temperature. The transmittance clearly decreases with increasing temperature, which would enhance the PL intensity of the PNIPAm polymers. Because no traditional fluorophores are present in the PNIPAm main chain, their fluorescence was unexpected. This interesting phenomenon has already been reported by some groups [4252]. Wu et al. reported hyperbranched poly(amino ester) could also emit blue photoluminescence without oxidation or protonation and proposed that the coexistence of tertiary amine and carbonyl groups in the core was the key structural factor in inducing fluorescence [51]. Lin et al. reported that the fluorescence properties of HPEA were due to the relationship of its three-dimensional structure, but the linear polymer failed to show any fluorescence [52], and the mechanism is still unresolved. They proposed that the hyperbranched polymers are highly cascaded with threedimensional globular architectures, which is similar to PNIPAm above the LCST in this study. We believe that the intramolecular hydrogen-bonding interaction between the amide hydrogen and carbonyl in PNIPAm above the LCST is also an important phenomenon, and the aggregation of the PNIPAm chain could enhance the emission properties. In addition, a protic solvent-like water can act as a hydrogenbonding donor for the interior oxygen atoms and stabilize the molecular conformation [52]. Due to the constrained 
geometric freedom and relatively rigid structure above the LCST, these star polymers exhibit an intrinsic fluorescent behavior.

\section{Conclusions}

The molecular weight, chemical structure, and photoluminescence properties of star PNIPAm- $b$-POSS copolymers are characterized by GPC, FTIR, and NMR and indicate that we have successfully synthesized a novel octa-functionalized PNIPAm POSS (PNIPAm- $b$-POSS) from $\mathrm{N}_{3}$-POSS and alkyne-PNIPAm via click chemistry. More interestingly, we found that these star polymers exhibited strong blue photoluminescence in water when above a lower critical solution temperature (LCST). This photoluminescence was likely due to the constrained geometric freedom and relative rigid structure caused by intramolecular hydrogen bonding within the star PNIPAm dentritic polymers, which exhibit an intrinsic fluorescent behavior.

\section{Acknowledgments}

This work was supported financially by the National Science Council, Taiwan, under Contract no. NSC 100-2221-E-110029-MY3 and NSC 100-2628-E-110-001. The authors do not have a direct financial relation with POSS, Hybrid Plastics Co., USA, Tokyo Chemical Industrial Co., and Brookhaven Instruments Corporation that might lead to a conflict of interests for any of the authors.

\section{References}

[1] H. K. Fu, S. W. Kuo, C. F. Huang, F. C. Chang, and H. C. Lin, "Preparation of the stimuli-responsive ZnS/PNIPAM hollow spheres," Polymer, vol. 50, no. 5, pp. 1246-1250, 2009.

[2] C. J. Huang and F. C. Chang, "Using click chemistry to fabricate ultrathin thermoresponsive microcapsules through direct covalent layer-by-layer assembly," Macromolecules, vol. 42, no. 14, pp. 5155-5166, 2009.

[3] C. J. Huang and F. C. Chang, "Polypeptide diblock copolymers: syntheses and properties of poly $(\mathrm{N}$-isopropylacrylamide)-b-polylysine," Macromolecules, vol. 41, no. 19, pp. 70417052, 2008.

[4] H. Ringsdorf, J. Venzmer, and F. M. Winnik, "Fluorescence studies of hydrophobically modified poly(N-isopropylacrylamides)," Macromolecules, vol. 24, no. 7, pp. 1678-1686, 1991.

[5] P. Kujawa, F. Tanaka, and F. M. Winnik, "Temperaturedependent properties of telechelic hydrophobically modified poly $(\mathrm{N}$-isopropylacrylamides) in water: evidence from light scattering and fluorescence spectroscopy for the formation of stable mesoglobules at elevated temperatures," Macromolecules, vol. 39, no. 8, pp. 3048-3055, 2006.

[6] C. F. Huang, H. F. Lee, S. W. Kuo, H. Xu, and F. C. Chang, "Star polymers via atom transfer radical polymerization from adamantane-based cores," Polymer, vol. 45, no. 7, pp. 22612269, 2004.

[7] C. F. Huang, S. W. Kuo, H. C. Lin et al., "Thermal properties, miscibility and specific interactions in comparison of linear and star poly(methyl methacrylate) blend with phenolic," Polymer, vol. 45, no. 17, pp. 5913-5921, 2004.

[8] J. Xia, X. Zhang, and K. Matyjaszewski, "Synthesis of starshaped polystyrene by atom transfer radical polymerization using an "arm first" approach," Macromolecules, vol. 32, no. 13, pp. 4482-4484, 1999.

[9] H. Gao and K. Matyjaszewski, "Synthesis of star polymers by a combination of ATRP and the "click" coupling method," Macromolecules, vol. 39, no. 15, pp. 4960-4965, 2006.

[10] W. Zhang and A. H. E. Müller, "A "click chemistry" approach to linear and star-shaped telechelic POSS-containing hybrid polymers," Macromolecules, vol. 43, no. 7, pp. 3148-3152, 2010.

[11] S.-W. Kuo and F.-C. Chang, "POSS related polymer nanocomposites," Progress in Polymer Science, vol. 36, no. 12, pp. 16491696, 2011.

[12] Q. Pan, X. Chen, X. Fan, Z. Shen, and Q. Zhou, "Organicinorganic hybrid bent-core liquid crystals with cubic silsesquioxane cores," Journal of Materials Chemistry, vol. 18, no. 29, pp. 3481-3488, 2008.

[13] Y. J. Lee, J. M. Huang, S. W. Kuo, and F. C. Chang, "Lowdielectric, nanoporous polyimide films prepared from PEOPOSS nanoparticles," Polymer, vol. 46, no. 23, pp. 1005610065, 2005.

[14] B. H. Yang, H. Y. Xu, Z. Z. Yang, and X. Y. Liu, "Design and architecture of low-dielectric-constant organic-inorganic hybrids from octahydridosilsesquioxanes," Journal of Materials Chemistry, vol. 19, no. 47, pp. 9038-9044, 2009.

[15] Y. L. Liu and M. H. Fangchiang, "Polyhedral oligomeric silsesquioxane nanocomposites exhibiting ultra-low dielectric constants through POSS orientation into lamellar structures," Journal of Materials Chemistry, vol. 19, no. 22, pp. 3643-3647, 2009.

[16] Y. J. Lee, J. M. Huang, S. W. Kuo, J. S. Lu, and F. C. Chang, "Polyimide and polyhedral oligomeric silsesquioxane nanocomposites for low-dielectric applications," Polymer, vol. 46, no. 1, pp. 173-181, 2005.

[17] T. Hirai, M. Leolukman, T. Hayakawa, M. A. Kakimoto, and P. Gopalan, "Hierarchical nanostructures of organosilicate nanosheets within self-organized block copolymer films," Macromolecules, vol. 41, no. 13, pp. 4558-4560, 2008.

[18] C. H. Lu, J. H. Wang, F. C. Chang, and S. W. Kuo, "Star block copolymers through nitroxide-mediated radical polymerization from polyhedral oligomeric silsesquioxane (POSS) core," Macromolecular Chemistry and Physics, vol. 211, no. 12, pp. 1339-1347, 2010.

[19] C. H. Lu, S. W. Kuo, W. T. Chang, and F. C. Chang, "The selfassembled structure of the diblock copolymer PCL-b-P4VP transforms upon competitive interactions with octaphenol polyhedral oligomeric silsesquioxane," Macromolecular Rapid Communications, vol. 30, no. 24, pp. 2121-2127, 2009.

[20] W. B. Zhang, B. Sun, H. Li et al., "Synthesis of in-chainfunctionalized polystyrene-block-poly(dimethylsiloxane) diblock copolymers by anionic polymerization and hydrosilylation using dimethyl-4-(1-phenylvinyl)phenylsilane," Macromolecules, vol. 42, no. 19, pp. 7258-7262, 2009.

[21] Y. Ni and S. Zheng, "A novel photocrosslinkable polyhedral oligomeric silsesquioxane and its nanocomposites with poly(vinyl cinnamate)," Chemistry of Materials, vol. 16, no. 24, pp. 5141-5148, 2004.

[22] H. M. Lin, S. Y. Wu, P. Y. Huang, C. F. Huang, S. W. Kuo, and F. C. Chang, "Polyhedral oligomeric silsesquioxane containing copolymers for negative-type photoresists," Macromolecular Rapid Communications, vol. 27, no. 18, pp. 1550-1555, 2006.

[23] H. Xu, S. W. Kuo, J. S. Lee, and F. C. Chang, "Preparations, thermal properties, and Tg increase mechanism of 
inorganic/organic hybrid polymers based on polyhedral oligomeric silsesquioxanes," Macromolecules, vol. 35, no. 23, pp. 8788-8793, 2002.

[24] H. Xu, S. W. Kuo, J. S. Lee, and F. C. Chang, "Glass transition temperatures of poly(hydroxystyrene-co-vinylpyrrolidoneco-isobutylstyryl polyhedral oligosilsesquioxanes)," Polymer, vol. 43, no. 19, pp. 5117-5124, 2002.

[25] Y. C. Sheen, C. H. Lu, C. F. Huang, S. W. Kuo, and F. C. Chang, "Synthesis and characterization of amorphous octakisfunctionalized polyhedral oligomeric silsesquioxanes for polymer nanocomposites," Polymer, vol. 49, no. 18, pp. 4017-4024, 2008.

[26] S. W. Kuo, H. F. Lee, W. J. Huang, K. U. Jeong, and F. C. Chang, "Solid state and solution self-assembly of helical polypeptides tethered to polyhedral oligomeric silsesquioxanes," Macromolecules, vol. 42, no. 5, pp. 1619-1626, 2009.

[27] S. W. Kuo, Y. C. Wu, C. H. Lu, and F. C. Chang, "Surface modification of gold nanoparticles with polyhedral oligomeric silsesquioxane and incorporation within polymer matrices," Journal of Polymer Science B, vol. 47, no. 8, pp. 811-819, 2009.

[28] K. W. Huang, L. W. Tsai, and S. W. Kuo, "Influence of octakisfunctionalized polyhedral oligomeric silsesquioxanes on the physical properties of their polymer nanocomposites," Polymer, vol. 50, no. 20, pp. 4876-4887, 2009.

[29] R. S. Shih, C. H. Lu, S. W. Kuo, and F. C. Chang, "Hydrogen bond-mediated self-assembly of polyhedral oligomeric silsesquioxane-based supramolecules," Journal of Physical Chemistry C, vol. 114, no. 30, pp. 12855-12862, 2010.

[30] Y.-C. Lin and S.-W. Kuo, "Self-assembly and secondary structures of linear polypeptides tethered to polyhedral oligomeric silsesquioxane nanoparticles through click chemistry," Journal of Polymer Science A, vol. 49, no. 10, pp. 2127-2137, 2011.

[31] J. Mu and S. Zheng, "Poly(N-isopropylacrylamide) nanocrosslinked by polyhedral oligomeric silsesquioxane: temperature-responsive behavior of hydrogels," Journal of Colloid and Interface Science, vol. 307, no. 2, pp. 377-385, 2007.

[32] K. Zeng, L. Wang, and S. Zheng, "Rapid deswelling and reswelling response of poly( $N$-isopropylacrylamide) hydrogels via formation of interpenetrating polymer networks with polyhedral oligomeric silsesquioxane-capped polyethylene oxide amphiphilic telechelics," Journal of Physical Chemistry B, vol. 113, no. 35, pp. 11831-11840, 2009.

[33] K. Zeng, Y. Fang, and S. Zheng, "Organic-inorganic hybrid hydrogels involving poly( $\mathrm{N}$-isopropylacrylamide) and polyhedral oligomeric silsesquioxane: preparation and rapid thermoresponsive properties," Journal of Polymer Science B, vol. 47, no. 5, pp. 504-516, 2009.

[34] W. Zhang, L. Liu, X. Zhuang, X. Li, J. Bai, and Y. Chen, "Synthesis and self-assembly of tadpole-shaped organic/inorganic hybrid poly(N-isopropylacrylamide) containing polyhedral oligomeric silsesquioxane via RAFT polymerization," Journal of Polymer Science A, vol. 46, no. 21, pp. 7049-7061, 2008.

[35] Y. C. Wu and S. W. Kuo, "Synthesis and characterization of polyhedral oligomeric silsesquioxane (POSS) with multifunctional benzoxazine groups through click chemistry," Polymer, vol. 51, no. 17, pp. 3948-3955, 2010.

[36] S. W. Kuo and H. T. Tsai, "Control of peptide secondary structure on star shape polypeptides tethered to polyhedral oligomeric silsesquioxane nanoparticle through click chemistry," Polymer, vol. 51, no. 24, pp. 5695-5704, 2010.
[37] M. Ciampolini and N. Nardi, "Five-coordinated high-spin complexes of bivalent cobalt, nickel, and copper with tris(2dimethylaminoethyl)amine," Inorganic Chemistry, vol. 5, no. 1, pp. 41-44, 1966.

[38] C.-T. Lai, R.-H. Chien, S.-W. Kuo, and J.-L. Hong, "Tetraphenylthiophene-functionalized poly(n-isopropylacrylamide): probing lcst with aggregation-induced emission," Macromolecules, vol. 44, no. 16, pp. 6546-6556, 2011.

[39] W. Zhang and A. H. E. Müller, "Synthesis of tadpole-shaped POSS-containing hybrid polymers via "click chemistry"," Polymer, vol. 51, no. 10, pp. 2133-2139, 2010.

[40] Y.-S. Ye, W.-C. Shen, C.-Y. Tseng et al., "Versatile grafting approaches to star-shaped POSS-containing hybrid polymers using RAFT polymerization and click chemistry," Chemical Communications, vol. 47, no. 38, pp. 10656-10658, 2011.

[41] J. Zhu, X. Zhu, E. T. Kang, and K. G. Neoh, "Design and synthesis of star polymers with hetero-arms by the combination of controlled radical polymerizations and click chemistry," Polymer, vol. 48, no. 24, pp. 6992-6999, 2007.

[42] W. I. Lee, Y. Bae, and A. J. Bard, "Strong blue photoluminescence and ECL from OH-terminated PAMAM dendrimers in the absence of gold nanoparticles," Journal of the American Chemical Society, vol. 126, no. 27, pp. 8358-8359, 2004.

[43] D. Wang and T. Imae, "Fluorescence emission from dendrimers and its $\mathrm{pH}$ dependence," Journal of the American Chemical Society, vol. 126, no. 41, pp. 13204-13205, 2004.

[44] D. Onoshima and T. Imae, "Dendritic nano- and microhydrogels fabricated by triethoxysilyl focal dendrons," Soft Matter, vol. 2, no. 2, pp. 141-148, 2006.

[45] D. Wang, T. Imae, and M. Miki, "Fluorescence emission from PAMAM and PPI dendrimers," Journal of Colloid and Interface Science, vol. 306, no. 2, pp. 222-227, 2007.

[46] O. Yemul and T. Imae, "Synthesis and characterization of poly(ethyleneimine) dendrimers," Colloid and Polymer Science, vol. 286, no. 6-7, pp. 747-752, 2008.

[47] K. Tamano and T. Imae, "Investigation of Luminescent poly(propylene imine) dendrimer," Journal of Nanoscience and Nanotechnology, vol. 8, no. 9, pp. 4329-4334, 2008.

[48] C. C. Chu and T. Imae, "Fluorescence investigations of oxygen-doped simple amine compared with fluorescent PAMAM dendrimer," Macromolecular Rapid Communications, vol. 30, no. 2, pp. 89-93, 2009.

[49] L. Pastor-Pérez, Y. Chen, Z. Shen, A. Lahoz, and S. E. Stiriba, "Unprecedented blue intrinsic photoluminescence from hyperbranched and linear polyethylenimines: polymer architectures and pH-effects," Macromolecular Rapid Communications, vol. 28, no. 13, pp. 1404-1409, 2007.

[50] M. J. Jasmine and E. Prasad, "Fractal growth of PAMAM dendrimer aggregates and its impact on the intrinsic emission properties," Journal of Physical Chemistry B, vol. 114, no. 23, pp. 7735-7742, 2010.

[51] D. Wu, Y. Liu, C. He, and S. H. Goh, "Blue photoluminescence from hyperbranched poly(amino ester)s," Macromolecules, vol. 38, no. 24, pp. 9906-9909, 2005.

[52] Y. Lin, J. W. Gao, H. W. Liu, and Y. S. Li, "Synthesis and characterization of hyperbranched poly(ether amide)s with thermoresponsive property and unexpected strong blue photoluminescence," Macromolecules, vol. 42, no. 9, pp. 32373246, 2009. 

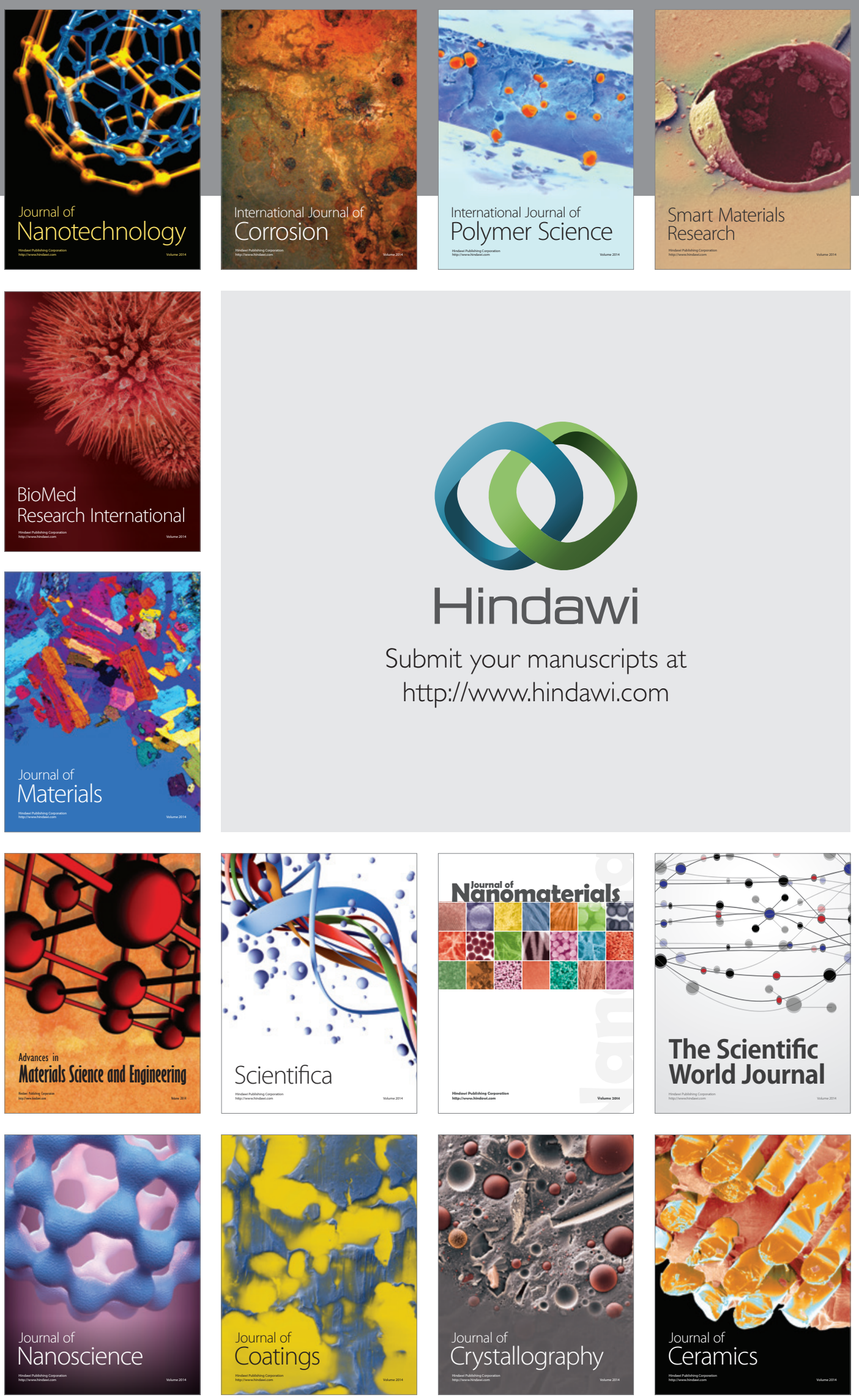

The Scientific World Journal

Submit your manuscripts at

http://www.hindawi.com

\section{World Journal}

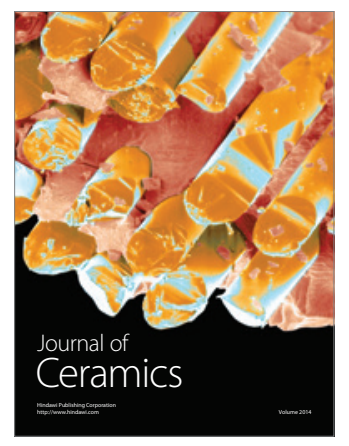

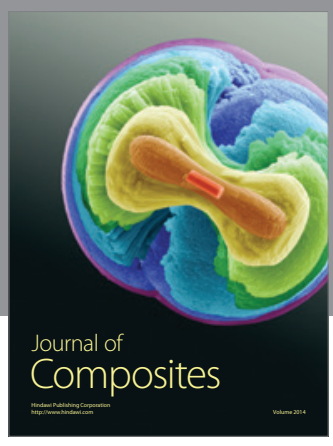
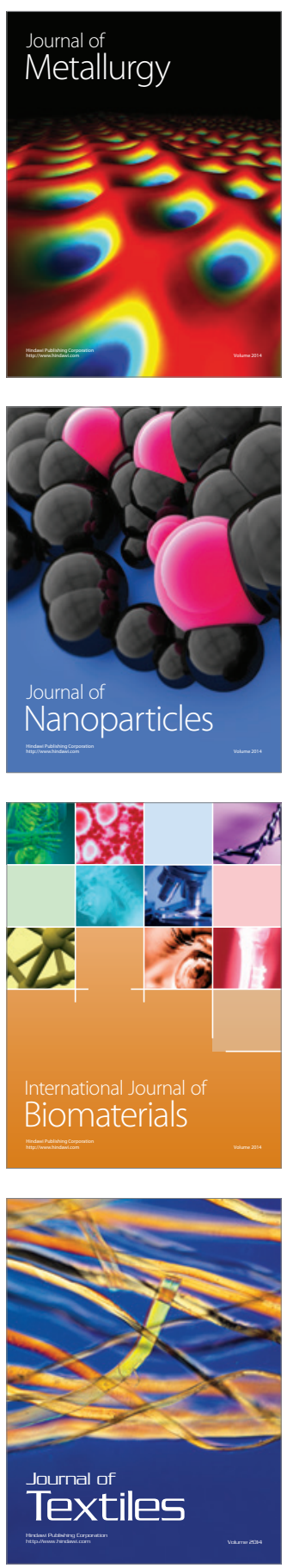